\title{
Surgical abortion in second trimester: Initial experiences in Nepal
}

Shrivastava $V^{1}$, Bajracharya $L^{2}$, Thapa $S^{2}$

${ }^{1}$ Department of Obstetrics and Gynaecology, Nepal Medical College, Jorpati, ${ }^{2}$ Paropakar Maternity and Women's Hospital, Thapathali

\begin{abstract}
Introduction: In spite of legalising abortion and making safe abortion available at affordable price at accessible distance to almost everyone, unsafe abortion especially second trimester abortion is still a big health problem in Nepal.

Objective: The objective of the study is to find the demographic profile, reasons for seeking abortion and to see the effectiveness of Misoprostol in preparing the cervix.

Materials and methods: A prospective study was done in the two second trimester abortion trainings conducted in Maternity hospital, Kathmandu. Total 57 clients had second trimester abortion performed. Information was collected from structured questionnaire and then data was analysed.

Results: Commonest reason for seeking abortion was, multiparity (61.4\%). Common reasons for second trimester abortion were, completed family size with unwanted pregnancy $(61.4 \%)$, unwanted pregnancy in married $(10.52 \%)$ unwanted pregnancy in unmarried (5.26\%).

Conclusions: Second trimester abortion is one of the most common procedures performed in reproductive-aged women and when performed by a skilled provider in the appropriate setting, it is one of the safest surgeries, if it is well supported by change in policy of the country and acceptability of the people.
\end{abstract}

Key words: Maternal death, Safe abortion, Second trimester abortion

I n 2002, Nepal took a great step towards improving the reproductive health and rights of women by legalising abortion ${ }^{1}$. It is estimated that Nepalese women get around 57,000 unsafe abortions every year. The facility is a boon for impoverished Nepal, where at least 20 percent of maternal mortality is caused by unsafe abortions $^{2}$. Between 2004 and 2007, 176 government, non-governmental organisation and private service sites were established throughout the country, giving women unprecedented access to safe abortion services ${ }^{3}$. The government of Nepal is in initial phases of training of second trimester abortion. Awareness regarding indications for demand and provision of second trimester abortion especially on mental health in both, clients and providers is another area of challenge ${ }^{3}$.

It was a prospective study, undertaken during both the training period, with the objectives to find out the demographic profile of the clients, reasons for seeking second trimester abortion.

\section{Material and methods}

The prospective observational study was conducted on June 10 to June 22, 2007 (first second trimester training) and March 14 to March 26, 2009 (second second trimester training) in Maternity Hospital, Kathmandu.
Total 57 women (first batch-23, second batch-34), who came for second trimester abortion were included in the study. Ethical approval with the patient was taken. A structured questionnaire was used to collect necessary information. The primary data was tabulated and analysed using Microsoft excel.

Results

Majority of the patients fell under age group 20-29 years followed by 30-39 years (Table 1).

Majority of the patients were multiparous 40 (70.18\%) followed by nulliparous $9(15.78 \%)$ and grand multiparous 8 (14.04\%) (Table 2). Almost 50\% of them were illiterate (Table 3 ).

As shown in Table 4 there were various reason for seeking abortion care of which majority had completed family size but had unwanted pregnancy 35 (61.4\%). These women had various reasons to come late for

Correspondence

Dr. Veena Shrivastava

Department of Obstetrics and Gynaecology

Nepal Medical College, Jorpati

E-mail: veenashrivastava@gmail.com 
termination and were mentally disturbed due to this pregnancy. Besides this group the others had lot of mental and social pressure because they were pregnant in unmarried state, they had received CAC service in first trimester but pregnancy continued and their contraceptives had failed. Few women came with pregnancy due to vasectomy, $\mathrm{Cu} \mathrm{T}$ and other method failure Other family planning methods used include barrier method of contraception and natural methods. Around $5 \%$ of women were rape victims and same number of women's pregnancy was terminated on medical ground.

Gestational age by clinical assessment at which Comprehensive abortion care was performed, ranged from 12 weeks to 22 weeks. Among them between 12-14 weeks were $32(56.14 \%)$ clients, between $15-16$ weeks were $21(36.84 \%)$ and $17-22$ weeks were $4(7.01 \%)$.

The range of duration of induction abortion interval was 4-13 hours.

Three cases could not have surgical abortion. In two cases, at the end of the day cervix was not found prepared for evacuation. Both were admitted in the hospital and had medical abortion. Both of them, expelled foetus spontaneously but had retained placenta, for which evacuation was done. The third case had 22 weeks pregnancy which was the result of rape, therefore, decided to do medical abortion. Total time taken for surgical evacuation- 15-30 minutes.

There was no major complication. Only three clients had minor problems. One had bleeding due to cervical injury; another had bleeding due to atony and third had transitory high fever, which were managed accordingly. After two weeks follow up, no complications were noted.

Table 1: Age wise distribution

\begin{tabular}{|c|c|}
\hline Age & Number (Percentage) \\
\hline 13-19 years & $3(5.26)$ \\
\hline 20-29 years & $37(64.91)$ \\
\hline $30-39$ years & $15(26.32)$ \\
\hline $40-45$ & $2(3.51)$ \\
\hline Total & $\mathbf{5 7}(\mathbf{1 0 0})$ \\
\hline
\end{tabular}

Table 2: Parity distribution

\begin{tabular}{|l|c|}
\hline Parity & Number (Percentage) \\
\hline Nulliparous & $9(15.78)$ \\
\hline Multiparous & $40(70.18)$ \\
\hline Grand multiparous & $8(14.04)$ \\
\hline Total & $\mathbf{5 7 ( 1 0 0 )}$ \\
\hline
\end{tabular}

Table 3: Literacy rate

\begin{tabular}{|l|c|}
\hline Literacy & Percentage (\%) \\
\hline Illiterate & $29(50)$ \\
\hline $\begin{array}{l}\text { Primary to secondary } \\
\text { education }\end{array}$ & $23(40)$ \\
\hline SLC and above & $5(8)$ \\
\hline
\end{tabular}

$\mathrm{SLC}=$ School leaving certificate

Table 4: Reasons for seeking abortion

\begin{tabular}{|c|c|c|}
\hline Reason for seeking abortion & Number & $\%$ \\
\hline 1. Mental indications & 51 & $89.4 \%$ \\
\hline \multirow{7}{*}{$\begin{array}{l}\text { 1.a. Married with unwanted } \\
\text { pregnancy due to completed } \\
\text { Family } \\
\text { 1.b.Married with unwanted } \\
\text { pregnancy due to other reasons } \\
\text { 1.c.Unmarried with unwanted } \\
\text { pregnancy } \\
\text { 1.d Failed abortion attempt in } \\
\text { first trimester } \\
\text { 1.e.Failed vasectomy } \\
\text { 1.f.Copper-T failure } \\
\text { 1.g.Other family planning } \\
\text { method failure }\end{array}$} & 35 & 61.4 \\
\hline & 6 & 10.52 \\
\hline & 3 & 5.26 \\
\hline & 1 & 1.75 \\
\hline & 1 & 1.75 \\
\hline & 1 & 1.75 \\
\hline & 4 & 7.01 \\
\hline 2.Medical disorder & 3 & 5.26 \\
\hline 3.Rape & 3 & 5.26 \\
\hline Total & 57 & 100 \\
\hline
\end{tabular}

Table 5: Induction abortion interval and number of doses of Misoprostol

\begin{tabular}{|c|c|c|}
\hline $\begin{array}{c}\text { Number } \\
\text { of doses of } \\
\text { Misoprostol }\end{array}$ & $\begin{array}{c}\text { Induction } \\
\text { abortion } \\
\text { interval }\end{array}$ & $\begin{array}{c}\text { Number } \\
\text { (Percentage) }\end{array}$ \\
\hline 1 & $4-5 \mathrm{hrs}$ & $14(24.56)$ \\
\hline 2 & $8-10 \mathrm{hrs}$ & $36(63.16)$ \\
\hline 3 & $12 .-13 \mathrm{hrs}$ & $4(7.02)$ \\
\hline
\end{tabular}


Table 6: Protocol used for surgical method of second trimester abortion.

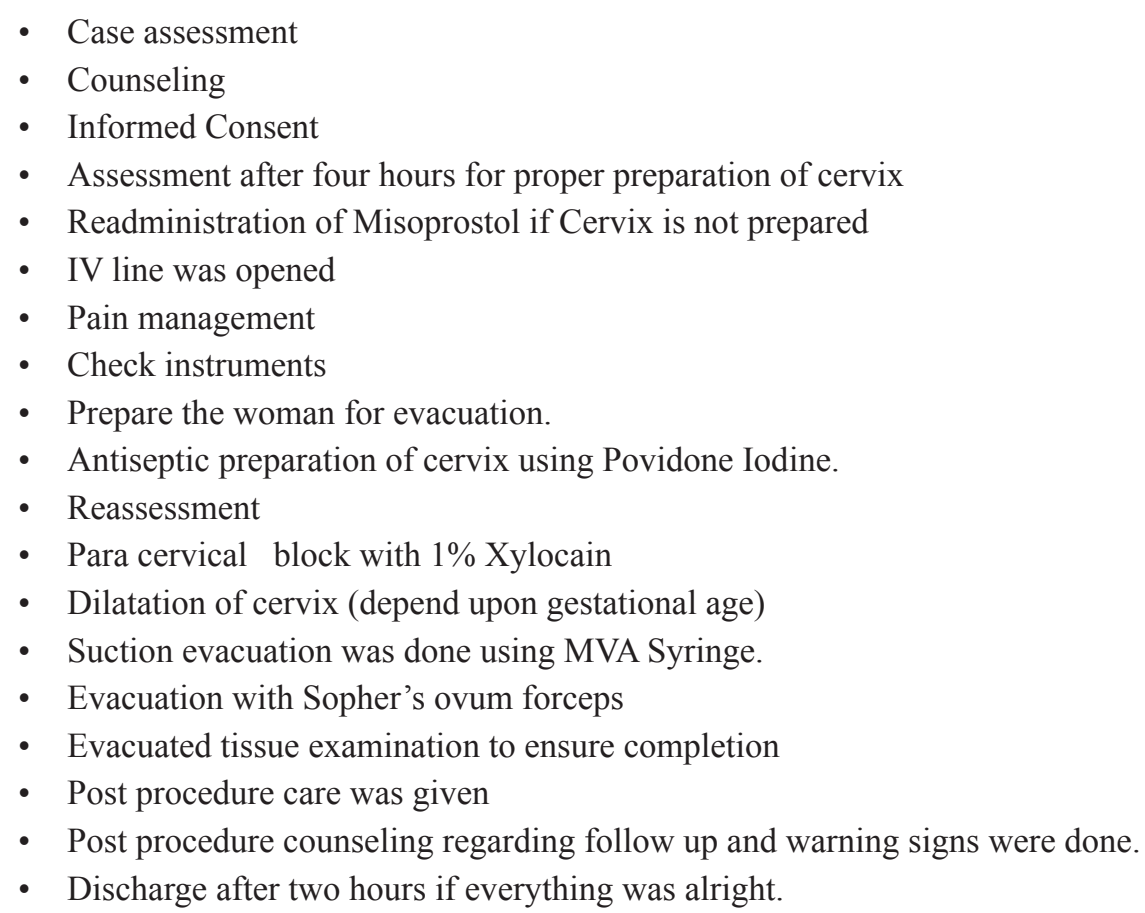

\section{Discussion}

The commonest reason for late abortion was completed family with unwanted pregnancy and unmarried with unwanted pregnancy. Service has been provided to many women for mental indication. There is no clear cut measurement of mental disturbance. It is done by service provider's subjective perception. There may be the possibility that women with more children, particularly those with more daughters or without a son, were seeking second-term abortion service on sex selective ground but service providers have to believe on what their clients are saying. Literatures claim that, two percent of all abortions to women with at least one living child were intended to avoid the birth of a female ${ }^{6}$. The reason in our set up might be due to late recognition of pregnancy due to irregular and prolong menstrual cycle, perimenopausal age or pregnancy occurring in young adolescent unmarried girls, who are not aware of pregnancy signs and symptoms. In all these cases, pregnancy is recognized only when foetal movement is felt by the person or protruding abdomen is seen by other people. We should also not forget the fact that congenital abnormalities are detected in second trimester only ${ }^{4,5}$. and number of clients seeking second trimester abortion service will be more if this indication is also added to the list.

The youngest client in this series was 14 years old who had no idea how pregnancy occurs. The oldest client was 45 years old who thought that the amenorrhea, she was having, is due to menopause, till she started feeling foetal movement and then she realised that she was pregnant. Most of the clients wanted termination because they already had the desired number of children (61.4\%). Having another child was going to put extra economical burden on their family. Abortion was performed on these women on mental health ground. Other reasons for abortion, were pregnancy occurring out of wedlock $(5.26 \%)$, result of rape, $(5.26 \%)$, or not ready for pregnancy in the present situation $(10.52 \%)$, family planning failure $(12.26 \%)$ and medical problem $(5.26 \%)$.

Among all, half $(50 \%)$ of them were illiterate and almost half $(40 \%)$ had come from faraway places. Young, poor, illiterate women are the ones, who commonly come with problem of second trimester abortion. Majority of those were multiparous and within the 20 to 29 age groups with most of them being multiparous and not desiring another children.

In this series $94.73 \%$ client could have their abortion done same day (within 4 to 13 hours). 3(5.26\%) but could not have surgical abortion. It means that, the centre which is providing second trimester abortion didn't have the adequate facility for both medical and surgical method of abortion and they were also not well trained. A need for proper set up with more trained staff not only at tertiary level set up but at the regional 
level can only be achieved with a good general public awareness and subsequent changes at the policy level to get widespread acceptability ${ }^{7,8}$.

Some study also suggested that privacy, confidentiality, and a support person designated by them as factors that would greatly contribute to their satisfaction with the services. Maximising patient satisfaction is necessary for the program's success but will be challenging ${ }^{3}$.

Surgical abortion is one of the most common procedures performed in reproductive-aged women and when performed by a skilled provider in the appropriate setting, it is one of the safest surgeries. Though the risk of complications is low, it increases exponentially with gestational age. Factors increasing risk of morbidity may be demographic, such as increasing patient age; medical, such as prior caesarean delivery; and procedural, such as inadequate dilation ${ }^{9}$.

Since the study was prospective with no adequate number of cases, the generalization of the finding of the study may not truly reflect the exact picture at all levels of health care. The need for further better study to validate the finding cannot be neglected. However the social scenario and the changing trends and policy requirement for second trimester abortion is still an area to discuss and research.

\section{Conclusions}

Second trimester abortion services should get priority, as it is one of the major challenge which helps in ensuring reproductive health right of Nepalese women. It also highlights that provision of law which without implementation will not solve problem of unsafe abortion. This can have subsequent impact in improvement in better level of care, training of more manpower, easy accessibility and finally reduction in complication rates.

\section{Acknowledgments}

We would like to express our sincere gratitude to Director of Family Health Division, Director of maternity hospital, IPAS/Nepal, all the trainers, all staff of Comprehensive Abortion Care Unit of Maternity Hospital and co-trainees for their support in analysing this study.

\section{References}

1. Austin Cline. Abortion in Nepal [Homepage on the Internet]. updated on 2004 April 30[cited 2009]; Available from URL:http://atheism. about.com/b/2004/04/30/abortion-in-nepal.htm

2. Karki YB, Basnett I, Clark KA, Ganatra Ba, Stucke S. Abortion Research Evaluation Laws and Policies. Ipas.2008.

3. Hyman AG, Baird TL, Basnett I. Establishing second trimester abortion services: experiences in Nepal, Viet Nam and South Africa. Reprod Health Matters. 2008 May;16(31 Suppl):13544.

4. Han XY, Jin L, Fan GS, Xiang Y, Liu XY, Hao N, Cui QC. Fetal anomalies in second trimester in recent ten years: clinical analysis of 116 case. Zhonghua Yi Xue Za Zhi. 2009;89(15):1053-6.

5. Athanasiadis AP, Polychronou P, Mikos T, Pantazis K, Assimakopoulos E, Tzevelekis $F$ et al. Women's expectations and intention to terminate pregnancy in case of abnormal findings at the second trimester level II ultrasound scan. A prospective, questionnairebased, cross-sectional survey. Fetal Diagn Ther. 2009;25(2):255-63.

6. Bélanger D, Oanh KT. Second-trimester abortions and sex-selection of children in Hanoi, Vietnam. Popul Stud (Camb). 2009;63(2):16371.

7. Dalvie SS. Second trimester abortions in India. Reprod Health Matters. 2008;16(31 Suppl):3745.

8. Berer M. A critical appraisal of laws on second trimester abortion. Reprod Health Matters. 2008;16(31 Suppl):3-13.

9. Diedrich J, Steinauer J. Complications of surgical abortion. Clin Obstet Gynecol. 2009;52(2):20512. 